\title{
Senior citizens' acceptance of connected health technologies in their homes
}

\author{
By
}

Reza Etemad-Sajadi \& Gil Gomes Dos Santos

\begin{abstract}
Purpose - The objective of this paper is to focus on seniors' acceptance of the usage of connected healthcare technologies in their homes. We integrated into TAM (Technology Acceptance Model) several latent variables such as social presence, trust, and degree of intrusiveness perceived with the use of connected health technologies.

Design/methodology/approach - We distributed our survey by post to 605 seniors. We targeted elderly people using connected health technologies (assistive alarm, telecare, sensors, etc.) at home and/or receiving health care at home. We received 213 questionnaires back. As we had several latent variables, we used partial least squares (PLS), a variance-based structural equation modeling method.
\end{abstract}

Findings - The results show that the level of trust in these technologies impacts significantly the perception of usefulness and the degree of intrusiveness. In parallel, the degree of usefulness of these technologies impacts positively elderly people's intention to accept their usage. Finally, one can claim that the perception of the social presence with the use of these technologies impacts positively the degree of perceived usefulness, trust, and intrusiveness.

Research limitations - Our sample covers a population benefiting from similar connected health technologies. It was difficult to distinguish and interpret the added value of each technology separately. As more and more elderly people use or are least familiarizing themselves with a range of connected technologies it would be interesting to identify which sets of connected technologies contribute the most to a positive feeling of social presence.

Social implications - These results are particularly relevant to stakeholders in the health industry in their quest to improve their products/services. A better understanding of the relation that the elderly have with connected health technologies is an essential prerequisite to supporting the development of new solutions capable of meeting the specific needs of our seniors.

Originality/value - We want to apply the Technology Acceptance Model (TAM) to connected health technologies designed for elderly people and we also want to extend it by integrating the social presence, trust, and degree of intrusiveness variables to our research model. 


\section{INTRODUCTION}

Life expectancy is increasing worldwide. According to the World Health Organization (2011), this trend shows no sign of slowing in the coming years. Due to chronic health problems that arise with increased life expectancy, improving the quality of life of elderly people represents a major challenge for today's society. Faced with an exploding elderly population and longer life expectancies, seniors increasingly need care and new healthcare technologies that can be useful in improving their quality of life at home. Indeed, we have to rethink the way in which services are provided to the elderly.

Seniors expect and desire to stay at home as long as possible instead of going to nursing homes (Townsend et al., 2011; Demiris et al., 2004). Connected technologies cannot prevent transfer to a nursing home but may enable the elderly to stay in their houses for longer. Continuing home care is therefore becoming a pressing objective. In this context, connected technologies (e.g. assistive alarm, telecare, sensors, etc.) may play a key role. One such concept is the "smart home", which refers to a house equipped with technology that enhances the safety of elderly people at home and monitors their health (Demiris et al., 2004). The system is able to track the senior and trigger an alarm if any abnormal vital signs are detected (Virone et al., 2002). It is also able, for example, to collect data such as respiratory or sleeping disorders in order to have a better understanding of the senior's problems (Nishida et al., 2000). Obviously, the choice of the connected technology depends on the pathology, the context, and the kind of care desired. As mentioned by Höpflinger et al. (2011), although healthcare needs are the first cause of a transfer to a nursing home, other factors such as age-related fragility (increased risk of falls) or social, mental and economic problems (social isolation, depression, alcoholism and other addictions, poverty) also play a decisive role. Nevertheless, we have to ask ourselves 
several questions about these technologies that strengthen healthcare services, including: What can be done to facilitate the implementation of these technologies? Are seniors ready, willing and able to use them? Do they have trust in these solutions? How intrusive are these technologies? Can these technologies impact the perception of social presence? By answering the above mentioned research questions we expect to contribute to the enrichment of knowledge about the elderly's perception of smart home technologies.

The goal of this study is to improve the quality of life of elderly persons by focusing on the use of these connected technologies. We also want to focus on the feeling of social presence (the perception that there is personal human contact) with these connected technologies and the degree of trust of elderly people using these systems. In parallel, we want to identify the relationship between the degree of intrusiveness of these technologies and their acceptation by the elderly. We want to apply the Technology Acceptance Model (TAM) to connected health technologies designed for elderly people and we also want to extend it by integrating the social presence, trust, and degree of intrusiveness variables to our research model. To the best of our knowledge, this is something new for the academic world in this context.

\subsection{Connected Health Technologies}

Rapid technological advances have led to the development of a wide range of solutions to assist aging. While investigating the potential or the impact of these solutions, researchers have used multiple terms to classify these solutions according to their utility or their technological features. New delivery modes for healthcare, such as smart homes, are required to ensure quality as well as cost effectiveness for the services provided to an aging population (Townsend et al., 2011). Smart homes rely on data acquisition equipment and devices to assess the current status of residents and their environments (Alam et al., 2012). In addition, ambientassisted living (AAL) consists of assisted living technologies based on ambient intelligence 
(Rashidi and Mihailidis, 2013). These monitoring devices can be put into three categories: sensors (identifying the user's location, body temperature, etc.), physiological devices (monitoring the user's heart rate, blood flow velocity, etc.), and multimedia devices (displaying information, speaker voice command, etc.).

\section{THEORETICAL BACKGROUND AND HYPOTHESES}

According to TAM, the ease of use of a new technology will influence its perceived usefulness (Davis, 1989). Ease of use is a key factor to promote the usage of new technologies among older adults. Research points out several reasons for that. The ageing population is believed to have more diverse needs in relation to new technologies than younger populations given the lower level of IT literacy (when compared with younger populations) and the physical and cognitive limitations that may arise with ageing. These factors may affect the capability of seniors' to use different technologies (Lorenz and Oppermann, 2009). Thus, poor design of new technologies can render the adoption of new technologies difficult by elderly people (Fisher, 2014). This assumption is also supported by Coughlin et al. (2007). McEvoy (2006) also suggested that new health technologies need to be user-friendly to optimize their uptake with older adults. The difficulty in understanding the functioning of new technologies could negatively influence elders’ perceived usefulness regarding their own use of a technology. Therefore, we propose the following hypothesis:

H1. Ease of use has a positive influence on the usefulness.

Another important issue that we have to consider is the feeling of social presence through the use of these connected technologies. Indeed, social presence is described as the perception that there is personal, sociable, and sensitive human contact (Gefen and Straub, 
2004; Etemad-Sajadi, 2016). The impact of perception of social presence on the acceptance of robots and screen agents in eldercare was investigated by Heerink et al. (2009). Their study showed that the feeling of social presence was indirectly impacting the intention to use the technology. Bickmore et al. (2005), found that seniors can consider the feeling of social presence as positive if they believe the technology is beneficial to them. Therefore, we propose the following hypothesis:

\section{H2. Social presence has a positive influence on usefulness.}

Heerink et al. (2009)’s study showed that elders' perception of social presence can be predictive of perceived enjoyment when interacting with screen agents or robots. This is interesting as it suggests that the usage or presence of connected technologies in elders' homes can be perceived differently than in an intrusive fashion. Indeed, the presence or interaction with connected technologies is believed to potentially alleviate elders' loneliness (Broadent et al., 2009; Portet et al., 2013). On this basis, one might believe that the feeling of intrusiveness is not necessarily perceived badly if individuals are in need of a social presence. Thus, we propose the following hypothesis:

\section{H3. Social presence has a positive influence on intrusiveness.}

Several authors identified that the perception of social presence can affect user trust (Sung and Mayer, 2012; Gefen and Straub, 2004; Hassanein and Head, 2007; Etemad-Sajadi, 2016). According to these authors, the inclusion of social cues facilitates the building of trust. The feeling that, through the use of these technologies, there is a connection between the senior and the external world may reassure and increase the feeling of trust. It would be interesting in our context to identify if there is a relationship between these two variables. Therefore, we propose the following hypothesis: 
H4. Social presence has a positive influence on trust.

One important question that we have to ask ourselves is the role of trust in the perception of usefulness. In research conducted with older consumers, McCloskey (2006) found that trust has a significant effect on usefulness. The more a senior trusted a system, the higher his/her belief in its usefulness. Having trust in a technology is primordial for increasing its usage (Gefen and Straub, 2003; Kim, 2012). It can also increase users' enjoyment and emotional appeal to use that technology (Hassanein and Head, 2004; Zhang et al., 2014). Therefore, we propose the following hypothesis:

H5. Degree of trust has a positive influence on usefulness.

Ziefle and Holzinger (2011) explored the attitudes of users towards video-based monitoring systems for long-term care of elderly or disabled people in smart home environments. The authors found that trust and privacy are central requirements for the implementation of such technology in private spaces. The potential loss of privacy appears to raise concerns amongst elders depending on the range of activities they plan to do there (Lorenzen-Huber et al., 2011). According to Lorenzen-Huber et al. (2011) some activities are viewed as more privacy sensitive than other activities and therefore elders feel concerned about these activities being monitored, perhaps because such data could be fall into the wrong hands. Indeed, the monitoring of parameters or putting data to use beyond those explicitly agreed upon by users can undermine trust Mittelstadt et al. (2013). For Lorenzen-Huber et al. (2011), enhancing data transparency, inclusion of privacy awareness, and the development of userfriendly control over personal data are required to foster the adoption of these solutions amongst the elderly. Thus, given the importance of privacy for some activities one might believe that 
trust in connected health technologies and their related companies influences the degree of intrusion older people are willing to accept. Therefore, we propose the following hypothesis:

H6. The degree of trust decreases the degree of intrusiveness.

The intention to accept a new technology is driven by its perceived utility (Beach et al., 2009; Tomita et al., 2007). In another context, McCloskey (2006) found that for older Americans, ease of use of e-commerce transactions had a significant impact on usefulness, which in turn had a positive direct effect on usage (i.e. acceptance or intention to use). The authors explain that the perceived usefulness can be enhanced by making on-line shopping easy enough to overcome physical limitations that seniors might suffer from. This is congruent with extant research and underscores the idea that a facilitated interface or design can positively influence seniors' perceived usefulness. Melenhorst et al. (2006) also found that the perceived benefits of the technology was an important factor in its adoption. Therefore, we propose the following hypothesis:

H7. Usefulness has a positive influence on intention to accept.

In this research we also want to see if there is a relationship between the degree of intrusion of these technologies and their acceptance by the elderly. Arcelus et al. (2007) mentioned the difficulty for elderly people to accept having their daily lives monitored by different health systems. It can be perceived intrusive and they can reject their usage. Access to personal health information (e.g., medication compliance, daily life activities and vital signals) can potentially be perceived as intrusive, raising privacy concerns (Parra et al., 2013). As carrying alarms, devices or sensors can be perceived as physically obtrusive, they need to be designed carefully (Melenhorst et al., 2004). Himmel and Ziefle (2016) found that visual monitoring is not well accepted by seniors. They compared various domestic spaces (living room, home office, kitchen, bedroom, and bathroom) and identified that the acceptance of 
visual monitoring is negative. It seems to be too intrusive and infringes on seniors' privacy. Townsend et al. (2011) found that seniors are willing to accept monitoring technologies that improve their autonomy. They found that even video cameras (very intrusive method) were accepted in exchange for increased autonomy. Several studies (Rialle et al., 2008; Ziefle and Wilkowska, 2010), found that the degree of acceptance of intrusive technology varies with the severity of the pathology of the elderly person being supported. Consequently, smart homes must be designed to protect privacy and should provide reassurance regarding who is going to access the private data that is collected (Portet et al., 2013). In our context, the technologies used are not based on visual monitoring. Nevertheless, we believe it is worthwhile to explore the relationship between the degree of perceived intrusiveness and the intention to accept or refuse the use of these connected health technologies. Therefore, we propose the following hypothesis:

H8. Degree of intrusiveness has a positive influence on intention to accept.

According to the literature, the facets of trust are reliability, ability, integrity, benevolence, and honesty (Kumar, 1996; Geffen and Straub, 2004). Having trust in a technology is primordial for increasing the desire to use it in the future (Gefen and Straub, 2003; Kim, 2012). Furthermore, another aspect of trust is what will be done with these data. Since the system receives information of vital importance, the system has to make sure that the information reaches only the right people. Thus, connected health technologies must be respectful of privacy and should provide reassurance regarding who is going to access the collected private data (Portet et al., 2013).

H9. Degree of trust has a positive influence on intention to accept. 
Figure 1 depicts our research model. We employed the technology acceptance model (TAM), which describes the intention to accept or use a new technology (Davis, 1989). The original TAM has been widely used to explain technology adoption. As connected health technologies are a type of information technology, users’ attitudes can be partially explained by TAM (Cyr et al., 2007; Etemad-Sajadi, 2014; Davis, 1989). According to TAM, the ease of use of a new technology will influence its perceived usefulness. In our case, we expanded the original TAM and integrated social presence, trust, and degree of intrusiveness.

Figure 1: Research model

\section{An extended version of TAM applied to connected healthcare technologies}

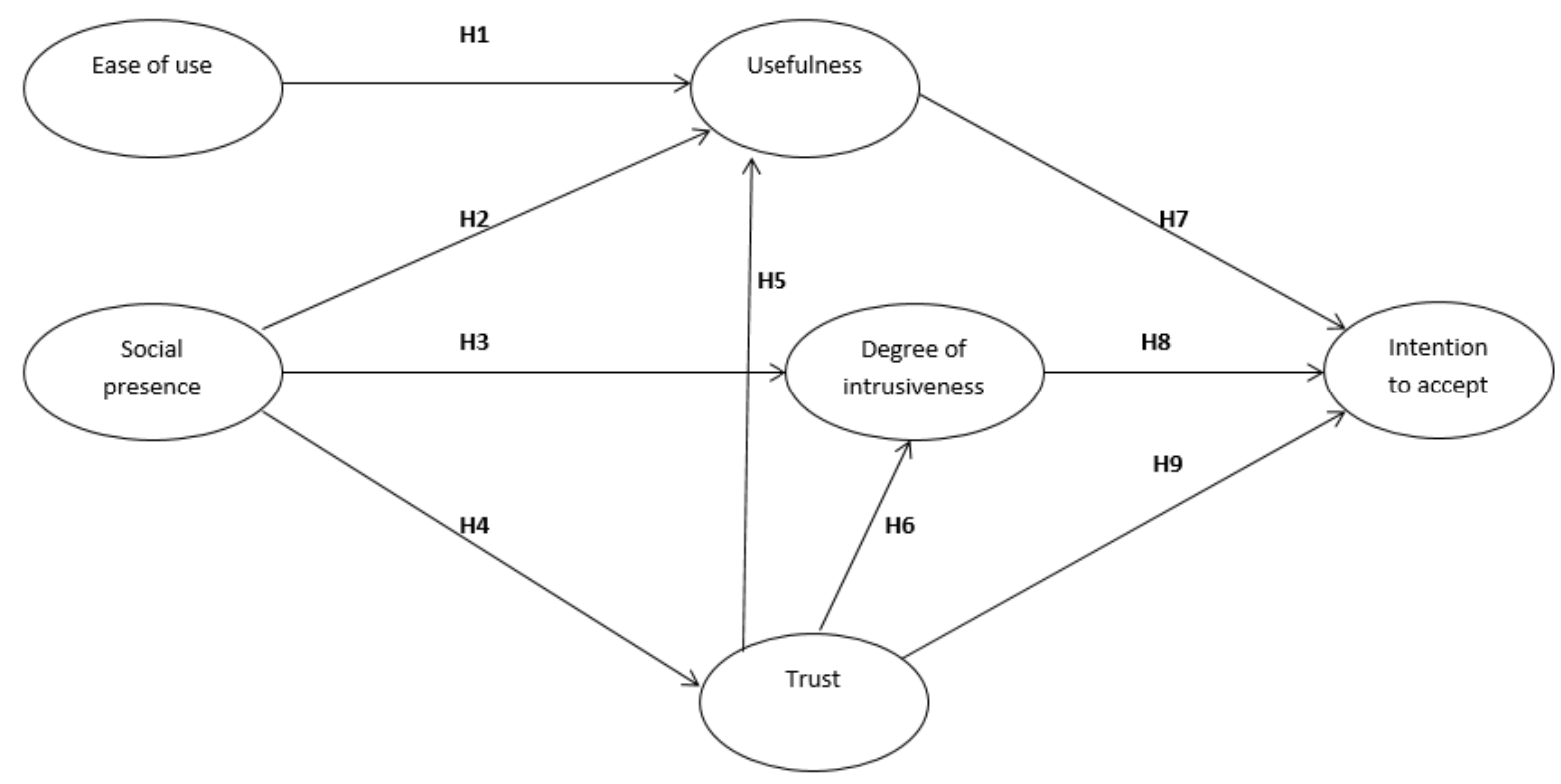

\section{METHODOLOGY}

\subsection{Measures}

Responses to the items presented below were used to create this current study's measures and to assess its hypothesized structural model. Response options for each item ranged from 1 (strongly disagree) to 7 (strongly agree). 
Ease of use and usefulness were assessed with items adapted from Steele et al. (2009), Cyr et al. (2007), and Davis (1989). Social presence was assessed with items adapted from Gefen and Straub (2003). Trust was assessed with items adapted from Steele et al. (2009), Gefen and Straub (2003), Gefen and Straub (2004), and Cyr et al. (2005). Degree of intrusiveness was assessed with items adapted from Li et al. (2002) and Steele et al. (2009). Finally, intention to accept was assessed with items adapted from Hellier et al. (2003). Table 1 summarizes our items.

Table 1: Questionnaire items

\begin{tabular}{|l|l|}
\hline Constructs & Items \\
\hline EASE OF USE & $\begin{array}{l}\text { It is easy to understand the use of this technology. } \\
\text { The use of this technology is practical. }\end{array}$ \\
\hline USEFULNESS & $\begin{array}{l}\text { This technology is useful. } \\
\text { This technology is efficient. } \\
\text { With this technology, I feel less anxious. }\end{array}$ \\
\hline SOCIAL PRESENCE & $\begin{array}{l}\text { The technology used makes me feel connected with the external world. } \\
\text { There is a sense of human contact through the use of this connected } \\
\text { technology. } \\
\text { The technology used makes me feel less dependent on people. }\end{array}$ \\
\hline TRUST & $\begin{array}{l}\text { I trust the reliability of information delivered by this system. } \\
\text { I trust this technology to keep personal information secure. } \\
\text { The technology used looks trustworthy. }\end{array}$ \\
\hline INTRUSIVENESS & $\begin{array}{l}\text { This technology is intrusive. } \\
\text { Through this technology, I feel that I am observed. }\end{array}$ \\
\hline INTENTION TO ACCEPT & $\begin{array}{l}\text { I intend to continue my use of this technology in the future. } \\
\text { The of this technology increases my quality of life. }\end{array}$ \\
\hline
\end{tabular}




\subsection{Sampling and data collection procedures}

For the distribution of the questionnaire, we had the opportunity to reach the clients of the Croix-Rouge (Neuchâtel), Secutel, and Domosafety. We sent the questionnaire by post (with a return stamped envelope) to 605 seniors. We targeted elderly people using connected health technologies (assistive alarm, telecare, sensors, etc.) at home (72.5\% of our sample have connected technologies) and/or receiving healthcare at home (63.3\% of our sample receive healthcare at home). As far as the technologies are concerned, our respondents use the traditional assistive alarm and/or sensors installed in the senior's house. We did not focus on more intrusive techniques such as cameras. Overall, we received 213 questionnaires back (34.9\%). Considering the profile of the respondents, we were very positively surprised by the high number of respondents. As far as gender is concerned, it was divided with $27.8 \%$ male and $72.2 \%$ female. The average age of the respondents was 82.10 . Finally, $64.9 \%$ were living alone, $22.8 \%$ with their husband or wife, and $12.3 \%$ did not answer if they live alone or not.

\subsection{Data analysis method}

Structural equation modeling (SEM) was adopted to test the hypotheses due to the fact that the model contains several latent variables. SmartPLS 2.0 was used for the analysis. We employed a bootstrapping method (200 sub-samples) to test the significant level of regression path coefficients (Hair et al., 2011). We used the blindfolding approach (cross-validated communality and redundancy). The cross-validated communality index measures the quality of the measurement model of each block. The quality of each structural equation is measured by the cv-redundancy index (i.e. Stone-Geisser $\mathrm{Q}^{2}$ ). The Stone-Geisser $\mathrm{Q}^{2}$ for usefulness, trust, degree of intrusiveness, and intention to accept is respectively $0.51,0.19,0.14$, and $0.39 . \mathrm{Q}^{2}$ measures the extent to which observed values are reconstructed by the model and its parameter estimates (Chin, 1998). The technique represents a synthesis of function fitting and crossvalidation (Henseler et al., 2009). If it is negative, the model has no predictive relevance; values 
around 0.15 indicate a medium predictive relevance and around 0.35 a high predictive relevance (Henseler et al., 2009; Hair et al., 2012). In this model, the independent variables are therefore good predictors for usefulness and intention to accept. For trust and degree of intrusiveness, the independent variables have a moderate predictive relevance.

\section{RESULTS}

\subsection{Descriptive analysis}

Table 2 shows the means and the loadings of each item. Comparing the averages together, one can claim that the highest item is the usefulness of the technology with an average of 6.03 on a scale from 1 to 7 . The level of trust is relatively high (respectively item $1=5.61$, item $2=5.77$, and item $3=5.78$ ). The level of social presence tends to be positive (respectively item $1=4.87$, item $2=4.68$, and item $3=4.40$ ). We observed that there is a significant positive correlation between the age of respondents and the perception of the social presence with these technologies $(\gamma=0.131)$. Concerning the degree of intrusiveness, we found an average of 2.79 and 3.28 for the two items. Gender has a significant impact on the degree of perceived intrusiveness. Men judge the connected technologies more intrusive than women $(\gamma=-0.118)$. We also observed that people who are living alone are more willing to accept the use of these technologies compared to people who are living with their husband or wife.

Table 2: Descriptive statistics and items' loadings

\begin{tabular}{lccccc} 
Constructs & $\begin{array}{c}\text { Item } \\
\text { loading }\end{array}$ & Mean & $\begin{array}{c}\text { Std } \\
\text { deviation }\end{array}$ & Min & Max \\
\hline 1. Ease of use & & & & & \\
\hline 1.1 It is easy to understand the use of this technology. & .840 & $\mathbf{5 . 5 5}$ & 1.544 & 1 & 7 \\
\hline 1.2 The use of this technology is practical. & .911 & $\mathbf{5 . 8 3}$ & 1.348 & 1 & \\
\hline 2. Usefulness & & & & & \\
\hline 2.1 This technology is useful. & & & & & \\
\hline
\end{tabular}


2.2 This technology is efficient.

$\mathbf{5 . 1 7} \quad 1.600$

1

2.3 With this technology, I feel less anxious.

\section{Social presence}

3.1 The technology used makes me feel connected with the external world.

$\begin{array}{lllll}.761 & 4.87 & 1.825 & 1 & 7\end{array}$

3.2 There is a sense of human contact through the use of this connected technology.

$\begin{array}{lllll}.784 & 4.68 & 1.889 & 1 & 7\end{array}$

3.3 The technology used makes me feel less dependent

.780

4.40

1.775

1

7
on people.

4. Trust

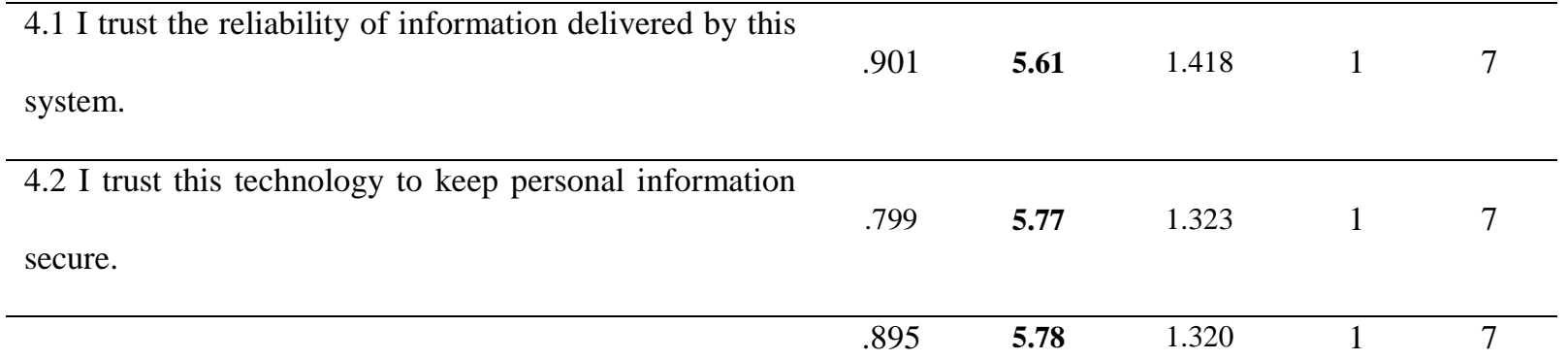

4.3 The technology used looks trustworthy.

\section{Degree of intrusiveness}

\begin{tabular}{lllllll}
\hline 5.1 This technology is intrusive. & .840 & $\mathbf{2 . 7 9}$ & 1.694 & 1 & 7 \\
\hline
\end{tabular}

5.2 Through this technology, I feel that I am observed.

\section{Intention to accept}

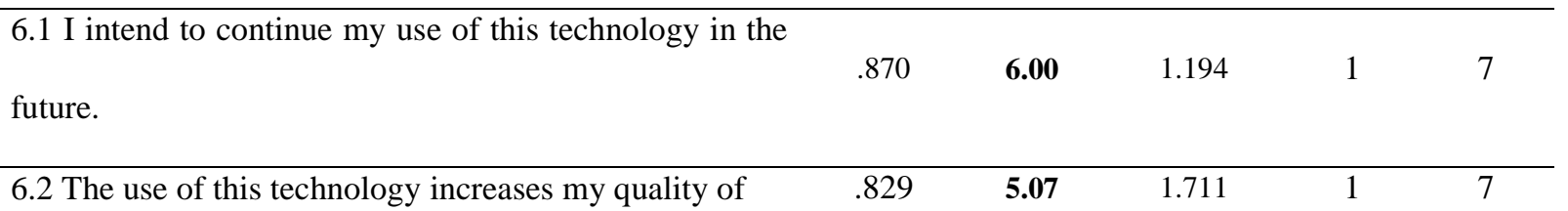
life.

\subsection{Reliability and validity of measures}

Table 3 shows that all latent variables have a composite reliability higher than 0.7 , confirming that the scale reliabilities have adequate and stable measurement properties. Convergent and discriminant validity are components of a larger measurement concept known as construct validity (Straub et al., 2004). Convergent validity is shown when each measurement item is strongly correlated with its construct. It is usually satisfied by retaining 
variables whose loadings are high, indicating that they share sufficient variance with their related construct. Discriminant validity is satisfied when each measurement item is weakly correlated with all other constructs except with the one with which it is theoretically associated (Gefen and Straub, 2005). With PLS, convergent and discriminant validities are confirmed if each construct AVE is larger than its correlation with other constructs. Moreover, each item should load more highly on its assigned construct than on the other constructs (Gefen et al., 2000; Straub et al., 2004). Table 3 shows the intercorrelation of the research constructs. The diagonal of this matrix represents the square root of the average variance extracted. For adequate discriminant validity, the diagonal elements should be significantly larger than the correlation of the specific construct with any of the other constructs and should be at least 0.5 (Fornell and Larcker, 1981). In our case, one can claim that discriminant validity is confirmed and sufficient to support the model.

Table 3: Reliability and discriminant validity

\begin{tabular}{|c|c|c|c|c|c|c|c|}
\hline Constructs & $\begin{array}{l}\text { Composite } \\
\text { reliability }\end{array}$ & 1 & 2 & 3 & 4 & 5 & 6 \\
\hline 1. Ease of use & .86 & .87 & & & & & \\
\hline 2. Usefulness & .88 & $.77 * *$ & .84 & & & & \\
\hline 3. Social presence & .81 & $.33 * *$ & $.53 * *$ & .77 & & & \\
\hline 4. Trust & .89 & $.66^{* *}$ & $.77^{* *}$ & $.50 * *$ & .86 & & \\
\hline 5. Degree of intrusiveness & .85 & -.11 & -.07 & $.32 *$ & -.11 & .86 & \\
\hline 6. Intention to accept & .83 & $.61^{* *}$ & .74 & $.60 * *$ & $.63 * *$ & -.01 & .84 \\
\hline $\begin{array}{ll}\text { Notes: } & \\
* & \text { Correlation is signif } \\
* * & \text { Correlation is signif } \\
\text { a } & \text { Diagonal: (Average }\end{array}$ & $\begin{array}{l}\text { he } 0.05 \text { level. } \\
\text { he } 0.01 \text { level. } \\
\text { Extracted) })^{1 / 2}\end{array}$ & $=\left(\Sigma \lambda_{\mathrm{i}}^{2} / \mathrm{n}\right)$ & & & & & \\
\hline
\end{tabular}

\subsection{Results and discussion}

Figure 2 presents the results of the PLS analysis and the values of different path coefficients. One can observe that ease of use impacts significantly usefulness $(\gamma=0.453)$. Hence $H 1$ is accepted. Social presence also has a significant impact on usefulness $(\gamma=0.177)$ even if the path coefficient is lower than for ease of use. In parallel, social presence positively impacts trust $(\gamma=0.507)$ and perceived degree of intrusiveness $(\gamma=0.503)$. Hence, $H 2, H 3$, and 
H4 are all accepted. Regarding the impact of trust on usefulness, one can claim that it is significant $(\gamma=0.381)$. Hence, $H 5$ is also accepted. Overall, $74.3 \%$ of usefulness is explained by ease of use, social presence, and trust. For H6, we found a significant negative correlation between trust and degree of intrusiveness $(\gamma=-0.350)$. In other words, the less respondents trust the connected technologies, the more they judge these tools intrusive. Therefore, $\mathrm{H} 6$ is confirmed. Finally, considering the intention to accept the use of these technologies, we found that only the perception of their usefulness impacts it significantly $(\gamma=0.636)$. The degree of intrusiveness and trust have no significant impact on intention to accept. $H 7$ is accepted, while H8 and H9 are both rejected.

Figure 2: Results of the PLS analysis

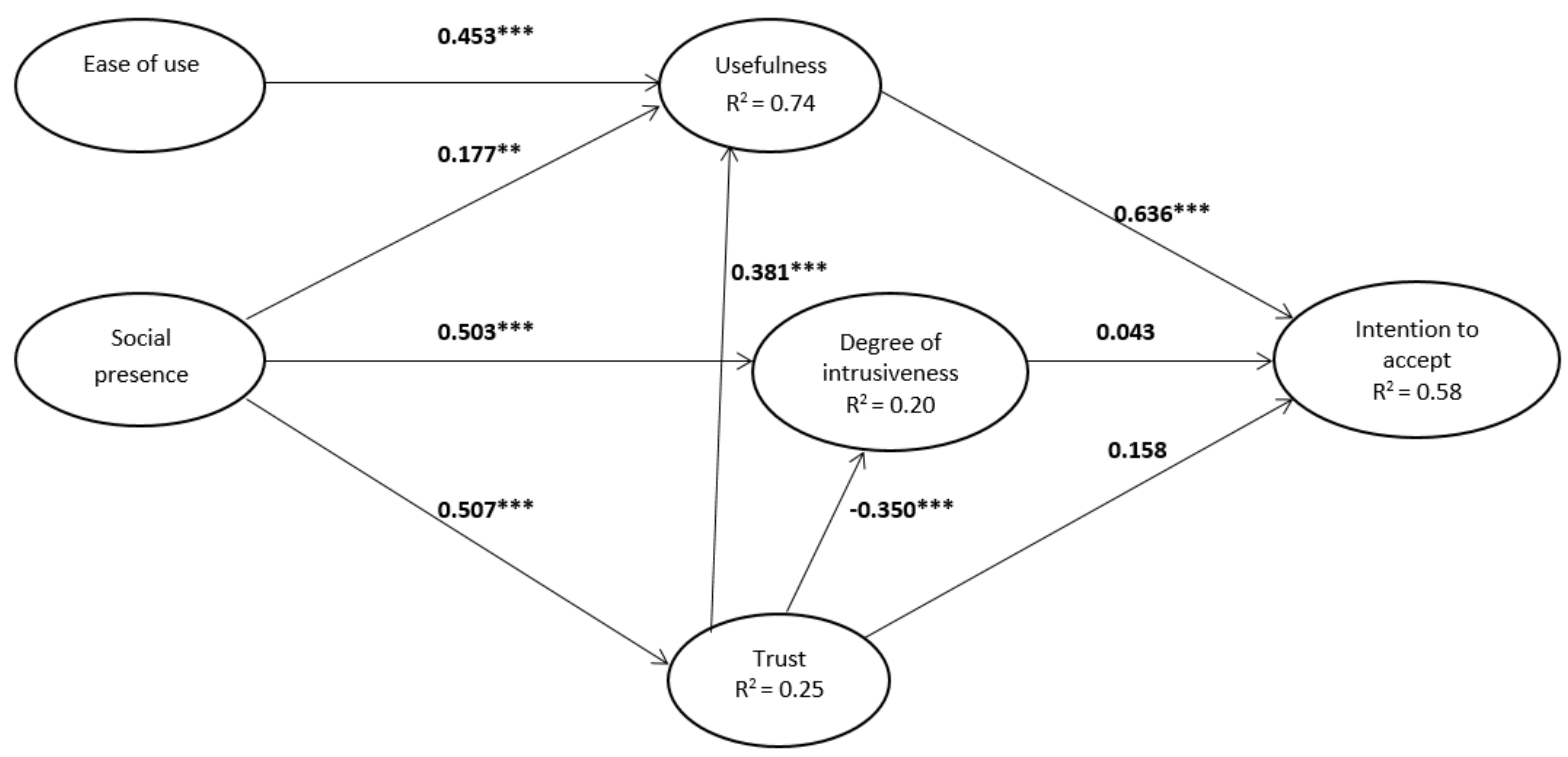

$\begin{array}{ll}\text { Notes: } & \\ * * & \text { Significant at } 0.01 \text { level } \\ * * * & \text { Significant at } 0.001 \text { level }\end{array}$

\section{CONCLUSION}

The aim of the study was to get a better understanding of how our seniors perceive connected health technologies in order to enhance their quality of life. The results regarding the 
positive influence of the feeling of social presence on the perceived usefulness, degree of intrusiveness, and the feeling of trust are particularly interesting. If the feeling of social presence heavily influences perceived intrusiveness and degree of trust, its moderate influence on perceived usefulness is also noteworthy. Indeed, this result is important as it indicates that the ability to generate a feeling of social presence can also be a key factor. Another interesting finding regarding the impact of social presence is that, the older the respondents are the more they perceive a social presence through these technologies. This raises the question of ascertaining what triggers this perception. For example, is this based on the type of technology used by this category of elders or simply a different relation to the technology while ageing? Further research is needed to explore the influence of age in the perception of these technologies.

Our study does not show that trust has a direct influence on intention to accept, although the relationship is very close to being significant. However, results show that trust has an indirect impact on the intention to accept by positively influencing perceived usefulness and by contributing to reduce the feeling of intrusiveness. We found that people who are living alone are more willing to accept the use of connected health technologies compared to people who are living with their husband or wife. Our results also showed that men tend to find these technologies more intrusive than women. Understanding why men are more sensitive to intrusiveness could be interesting for companies that develop these solutions, especially since this category of senior citizens is expected to grow in the next decades. If the feeling of intrusiveness has been identified in the literature as one of the main barriers to technology acceptance, our study did not find evidence of a direct influence of degree of intrusiveness on intention to accept these technologies. A possible explanation for this result is that respondents were already benefiting from these solutions and that this might change their perception about the degree of intrusiveness. 
Our hypothesis regarding the positive influence of usefulness on the intention to accept is also confirmed. That means that for our sample the perception of usefulness of these technologies will foster their acceptance. Although the relation of these two variables has been widely discussed in the literature, little empirical evidence relying on large samples has been provided so far. The present research contributes to filling this gap since the results are based on a survey that counted on the participation of more than 200 respondents.

Overall our research model is deemed reliable since seven hypotheses were confirmed out of nine. These results are particularly relevant to companies in their quest to improve their products/services and communication strategies. A better quality of healthcare services inclines to build satisfaction and loyalty among patients (Fatima et al., 2018). Indeed, a better understanding of the relation that the elderly have with connected health technologies is an essential prerequisite to supporting the development of new solutions capable of satisfying the specific needs of our seniors. Connected healthcare technologies can also reassure the family and avoid the difficult decision of opting for a nursing home or staying at home. We conclude with the observation that the next generation of seniors may be more eager to use new technologies as they will be more in touch with technology throughout their lives. It goes without saying that every senior citizen has specific medical needs that affect the extent to which they use connected health technologies. Therefore, we will have to follow along closely as the needs of the elderly evolve over time.

\subsection{Barriers to better usage of connected health technologies}

- Caregivers show a lack of enthusiasm for, and knowledge of, new technologies

- Financial issues and a lack of government participation (for example, teleassistance is not covered by Swiss health insurance law, LaMal)

- A lack of centralized data and coordination between different partners (food and health service providers, teleassistance, occupational therapists, etc.)

- $\quad$ Ethical issues (i.e. Where will the data will be stored? Who will have access to it ?)

\subsection{Some recommendations and challenges for home care service companies}


We believe it is time to rethink the way services are provided to the elderly. We have made recommendations - and highlighted some challenges - for home care service companies based on feedback from clients in our study:

- Keep the same hours for visits - ["Lack of precise time of visits", "Deliver services at a fixed and regular time", "Come on time", "Keep me informed about the time of visits.”]

- Retain the same employees (if possible) - ["I'd like to always have the same person", "No change of people”, "Have only two people taking care of me."]

- Improve communications between the service company and clients, family members and other home care providers

- Enhance socialization - ["Bring me out with my scooter", "Give me more mobility", "A person to eat with", "Break with loneliness".]

- Make clients feel more safe and secure through connected technologies - ["Will the alarm really work when I will need it? 24 hours a day?” (Possible solution: test the alarm at least once a month)]

- Increase socialization between neighbors in case of an emergency

\subsection{Limitations}

Our study has several limitations. First, our sample covers a population benefiting from similar connected health technologies. It was difficult to distinguish and interpret the added value of each technology separately. As more and more elderly people use or are least familiarizing themselves with a range of connected technologies it would be interesting to identify which sets of connected technologies contribute the most to a positive feeling of social presence. Our study is also limited to a population with a similar culture. Further research is needed to understand if the perception of connected health technologies differs according to cultural characteristics. In addition, our study only captures the opinion of senior citizens at a specific moment in time. Further research could investigate the degree to which the acceptance 
of connected health technologies changes while ageing or as they become increasingly familiar with such technologies.

\section{REFERENCES}

- Alam, M. R., Reaz, M. B. I., \& Ali, M. A. M. (2012). A review of smart homes - Past, present, and future. Systems, Man, and Cybernetics, Part C: Applications and Reviews, IEEE Transactions on, 42(6), 1190-1203.

- Arcelus, A., Jones, M. H., Goubran, R., \& Knoefel, F. (2007, May). Integration of smart home technologies in a health monitoring system for the elderly. In Advanced Information Networking and Applications Workshops, 2007, AINAW'07. 21st International Conference on (2, 820-825). IEEE.

- Beach, S., Schulz, R., Downs, J., Matthews, J., Barron, B., \& Seelman, K. (2009). Disability, age, and informational privacy attitudes in quality of life technology applications: Results from a national web survey. ACM Transactions on Accessible Computing (TACCESS), 2(1), $1-21$.

- Bickmore, T. W., Caruso, L., Clough-Gorr, K., \& Heeren, T. (2005). 'It’s just like you talk to a friend'relational agents for older adults. Interacting with Computers, 17(6), 711-735.

- Broadbent, E., Stafford, R., \& MacDonald, B. (2009). Acceptance of healthcare robots for the older population: review and future directions. International Journal of Social Robotics, 1(4), 319-330.

- Chin, W. W. (1998). The partial least squares approach to structural equation modeling. Modern Methods for Business Research, 295(2), 295-336.

- Coughlin, J. F., D'Ambrosio, L. A., Reimer, B., \& Pratt, M. R. (2007, August). Older adult perceptions of smart home technologies: implications for research, policy \& market innovations in healthcare. In Engineering in Medicine and Biology Society, 2007. EMBS 2007. 29th Annual International Conference of the IEEE (1810-1815). IEEE.

- Cyr, D., Hassanein, K., Head, M., \& Ivanov, A. (2007). The role of social presence in establishing loyalty in e-service environments. Interacting with Computers, 19(1), 43-56.

- Cyr, D., Bonanni, C., Bowes, J., \& Ilsever, J. (2005). Beyond trust: Web site design preferences across cultures. Journal of Global Information Management, 13(4), 24-52.

- Davis, F.D. (1989). Perceived usefulness, perceived ease of use, and user acceptance of information technology, MIS Quarterly, 13(3), 319-333.

- Demiris, G., Rantz, M. J., Aud, M. A., Marek, K. D., Tyrer, H. W., Skubic, M., \& Hussam, A. A. (2004). Older adults' attitudes towards and perceptions of smart home's technologies: a pilot study. Informatics for Health and Social Care, 29(2), 87-94.

- Etemad-Sajadi, R. (2016). The impact of online real-time interactivity on patronage intention: The use of avatars. Computers in Human Behavior, 61, 227-232.

- Etemad-Sajadi, R. (2014). The influence of a virtual agent on web-users' desire to visit the company: The case of restaurant's web site. International Journal of Quality \& Reliability Management, 31(4), 419-434.

- Fatima, T., Malik, S. A., \& Shabbir, A. (2018). Hospital healthcare service quality, patient satisfaction and loyalty: An investigation in context of private healthcare systems. International Journal of Quality \& Reliability Management, 35(6), 1195-1214.

- Fischer, S. H., David, D., Crotty, B. H., Dierks, M., \& Safran, C. (2014). Acceptance and use of health information technology by community-dwelling elders. International journal of medical informatics, 83(9), 624-635. 
- Fornell, C.R. and Larcker, D. (1981). Evaluating structural equation models with unobservable variables and measurement error, Journal of Marketing Research, 18 (1), 3950 .

- Gefen, D., \& Straub, D. (2005). A practical guide to factorial validity using PLS-Graph: Tutorial and annotated example. Communications of the Association for Information Systems, 16(1), 91-109.

- Gefen D. and Straub D. (2004). Consumer trust in B2C e-commerce and the importance of social presence: experiments in e-products and e-services, Omega, 32 (6), 407-425.

- Gefen, D., Karahanna, E., \& Straub, D.W. (2003).Trust and TAM in online shopping: an integrated model, MIS Quarterly, 27(1), 51-90.

- Gefen, D., Straub, D., \& Boudreau, M. C. (2000). Structural equation modeling and regression: Guidelines for research practice. Communications of the association for information systems, 4(1), 1-77.

- Hair, J. F., Sarstedt, M., Ringle, C. M., \& Mena, J. A. (2012). An assessment of the use of partial least squares structural equation modeling in marketing research. Journal of the Academy of Marketing Science, 40(3), 414-433.

- Hair, J. F., Ringle, C. M., \& Sarstedt, M. (2011). PLS-SEM: Indeed a silver bullet. The Journal of Marketing Theory and Practice, 19(2), 139-152.

- Hassanein, K. and Head, M. (2007). Manipulating perceived social presence through the web interface and its impact on attitude towards online shopping, International Journal of Human-Computer Studies, 65(8), 689-708.

- Hassanein, K., \& Head, M. (2004). The influence of product type on online trust. In Proceedings of 17th bled eCommerce conference.

- Heerink, M., Kröse, B., Evers, V., \& Wielinga, B. (2009). Influence of social presence on acceptance of an assistive social robot and screen agent by elderly users. Advanced Robotics, 23(14), 1909-1923.

- Hellier, P. K., Geursen, G. M., Carr, R. A., \& Rickard, J. A. (2003). Customer repurchase intention: A general structural equation model. European journal of marketing, 37(11/12), 1762-1800.

- Henseler, J., Ringle, C. M., \& Sinkovics, R. R. (2009). The use of partial least squares path modeling in international marketing. Advances in International Marketing, 20, 277-319.

- Hess, T. J., Fuller, M., \& Campbell, D. E. (2009). Designing interfaces with social presence: Using vividness and extraversion to create social recommendation agents. Journal of the Association for Information Systems, 10(12), 889-919.

- Himmel, S., \& Ziefle, M. (2016). Smart Home Medical Technologies: Users’ Requirements for Conditional Acceptance. i-com, 15(1), 39-50.

- Höpflinger, F., Bayer-Oglesby, L., \& Zumbrunn, A. (2011). La dépendance des personne âgées et les soins de longue durée: scénarios actualisés pour la Suisse. H. Huber.

- Kim, J. B. (2012). An empirical study on consumer first purchase intention in online shopping: integrating initial trust and TAM. Electronic Commerce Research, 12(2), 125150.

- Kumar, N. (1996). The power of trust in manufacturer-retailer relationships. Harvard business review, 74(6), 92-106.

- Lorenz, A., \& Oppermann, R. (2009). Mobile health monitoring for the elderly: Designing for diversity. Pervasive and Mobile Computing, 5(5), 478-495.

- Lorenzen-Huber, L., Boutain, M., Camp, L. J., Shankar, K., \& Connelly, K. H. (2011). Privacy, technology, and aging: A proposed framework. Ageing International, 36(2), 232252.

- Li, H., Edwards, S. M., \& Lee, J. H. (2002). Measuring the intrusiveness of advertisements: Scale development and validation. Journal of advertising, 31(2), 37-47. 
- McCloskey, D. W. (2006). The importance of ease of use, usefulness, and trust to online consumers: An examination of the technology acceptance model with older consumers. Journal of Organizational and End User Computing, 18(3), 47-65.

- McEvoy, S., Mulvenna, M., Bond, R., Nugent, C., \& Shapcott, M. (2006). Ageing people in Ireland: A survey perspective on technology in the home. Promoting Independence for Older Persons With Disabilities, 33-42.

- Melenhorst, A. S., Rogers, W. A., \& Bouwhuis, D. G. (2006). Older adults' motivated choice for technological innovation: evidence for benefit-driven selectivity. Psychology and aging, 21(1), 190.

- Melenhorst, A. S., Fisk, A. D., Mynatt, E. D., \& Rogers, W. A. (2004, September). Potential intrusiveness of aware home technology: Perceptions of older adults. In Proceedings of the Human Factors and Ergonomics Society Annual Meeting (48(2), 266-270). SAGE Publications.

- Mittelstadt, B., Fairweather, N. B., McBride, N., \& Shaw, M. (2013). Privacy, risk and personal health monitoring. In ETHICOMP 2013 conference proceedings (340-351).

- Nishida, Y., Hori, T., Suehiro, T., \& Hirai, S. (2000). Sensorized environment for selfcommunication based on observation of daily human behavior. In Intelligent Robots and Systems, 2000.(IROS 2000). Proceedings. 2000 IEEE/RSJ International Conference on (2, 1364-1372). IEEE.

- Parra, C., Silveira, P., Far, I. K., Daniel, F., De Bruin, E. D., Cernuzzi, L., \& Casati, F. (2013). Information Technology for Active Ageing: A Review of Theory and Practice. Interaction, 7(4), 351-448.

- Portet, F., Vacher, M., Golanski, C., Roux, C., \& Meillon, B. (2013). Design and evaluation of a smart home voice interface for the elderly: acceptability and objection aspects. Personal and Ubiquitous Computing, 17(1), 127-144.

- Rashidi, P., \& Mihailidis, A. (2013). A survey on ambient-assisted living tools for older adults. IEEE Journal of Biomedical and Health Informatics, 17(3), 579-590.

- Rialle, V., Ollivet, C., Guigui, C., \& Hervé, C. (2009). What do family caregivers of Alzheimer's disease patients desire in smart home technologies?. Methods Inf Med, 47 (1), 63-69.

- Steele, R., Lo, A., Secombe, C., \& Wong, Y. K. (2009). Elderly persons’ perception and acceptance of using wireless sensor networks to assist healthcare. International journal of medical informatics, 78(12), 788-801.

- Straub, D., Boudreau, M.C. and Gefen, D. (2004). Validation guidelines for IS positivist research. Communications of the Association for Information Systems, 14, 380-426.

- Sung, E., \& Mayer, R. E. (2012). Five facets of social presence in online distance education. Computers in Human Behavior, 28(5), 1738-1747.

- Tomita, M. R., Mann, W. C., Stanton, K., Tomita, A. D., \& Sundar, V. (2007). Use of currently available smart home technology by frail elders: process and outcomes. Topics in geriatric rehabilitation, 23(1), 24-34.

- Townsend, D., Knoefel, F., \& Goubran, R. (2011, August). Privacy versus autonomy: a tradeoff model for smart home monitoring technologies. InEngineering in Medicine and Biology Society, EMBC, 2011 Annual International Conference of the IEEE (pp. 47494752). IEEE.

- Virone, G., Noury, N., \& Demongeot, J. (2002). A system for automatic measurement of circadian activity deviations in telemedicine. IEEE Transactions on Biomedical Engineering, Vol. 49 No. 12, pp. 1463-1469.

- World Health Organization. (2011). Joint FA. 
- Zhang, K. Z., Cheung, C. M., \& Lee, M. K. (2014). Examining the moderating effect of inconsistent reviews and its gender differences on consumers' online shopping decision. International Journal of Information Management, 34(2), 89-98.

- Ziefle, M. \& Holzinger, A. (2011, July). Medical technology in smart homes: exploring the user's perspective on privacy, intimacy and trust. In Computer Software and Applications Conference Workshops (COMPSACW), 2011 IEEE 35th Annual (410-415). IEEE.

- Ziefle, M., \& Wilkowska, W. (2010, March). Technology acceptability for medical assistance. 4th ICST Conference on Pervasive Computing Technologies for Healthcare 2010. 